\title{
Personality and Intellectual Abilities as Predictors of Intelligent Behaviour
}

\author{
Diana Cárdenas \& Dale Stout \\ Bishop's University
}

\begin{abstract}
La présente étude a pour but d'examiner le rôle des habiletés intellectuelles et de la personnalité sur la présence de comportements intelligent. Le comportement est opérationnalisé comme étant la prise de bonnes décisions. Cet article prend en compte certaines caractéristiques personnelles qui devraient mener à la prise de bonnes décisions, telles que : la personnalité, l'intelligence émotionnelle et le bien-être psychologique. Il a été postulé que les différentes caractéristiques personnelles soient des variables modératrices ou médiatrices de la relation entre les habiletés intellectuelles et la prise de bonnes décisions. Quatre-vingt-dix-sept participants ont complété les tests servant à mesurer les variables mentionnées ci-dessus. L'analyse des résultats n'a révélé aucune corrélation statistiquement significative entre les habiletés intellectuelles et la prise de bonnes décisions, ni entre la personnalité et les comportements intelligents. Il est possible que ces résultats soient causés par un manque de variance due à un échantillon trop restreint.
\end{abstract}

Mot-clés : personnalité, intelligence, prise de décisions, comportement intelligent

\begin{abstract}
The purpose of this study is to examine the relationship between intellectual abilities and personality in predicting intelligent behaviour, operationalized as good decision-making practices. This examination considers certain personal characteristics that are hypothesized to lead to intelligent behaviour, namely personality, emotional intelligence and subjective well-being. The study aims at understanding how such personal characteristics influence decision making. It was hypothesized that the relationship between intellectual abilities and decision making would be mediated or moderated by the personal characteristics mentioned previously. Ninety-seven participants took tests that assessed these factors. The analysis of the data revealed no significant correlation between intellectual abilities and decision making, nor was there a correlation between any of the personality factors and decision making or intelligence. It is suspected that the homogeneous sample did not allow for enough variance to show any correlation. Methodological corrections are suggested for future studies.
\end{abstract}

Keywords: personality, intelligence, decision making, intelligent behaviour

Wechsler, the author of the Wechsler Adult Intelligence Scale (WAIS), argued that "general intelligence cannot be equated with intellectual abilities however broadly defined, but [general intelligence] must be regarded as a manifestation of the personality as a whole" (Zachary, 1990, p. 279). With this, he makes a distinction between intellectual abilities (the behaviour measured by intelligence tests) and general intelligence, defined as the "the aggregate or global

I express my gratitude to Dr. Stuart McKelvie for his ideas and collaboration and to the students at Bishop's University who made this study possible. Please address correspondence to Diana Cardenas (e-mail: diana.cardenas @umontreal.ca). capacity of the individual to act purposefully, to think rationally, and to deal effectively with his[/her] environment" (Wechsler, 1975, p. 3). General intelligence is defined in terms of concrete actions or behaviour and it is different from intellectual abilities in that the first is a broader and a more prevailing capacity. In addition, he suggests (Wechsler, 1975) that intellectual abilities are not perfect predictors of general intelligence or intelligent behaviour, meaning that to explain intelligent behaviour it is important to consider more than just intellectual abilities. The assessment of general intelligence needs to be based on both intellectual and non-intellectual factors, an important non-intellectual factor being personality. Wechsler, as quoted by Zachary (1990, p. 279), writes: "When our scales measure the non-intellective as well as the intellectual factors in intelligence, they will more 


\section{CÁRDENAS \& STOUT}

nearly measure what in actual life corresponds to intelligent behaviour", once more accentuating the importance of non-intellective factors in intelligent behaviour. The present study explores the nature of the relationship between some non-intellective factors (such as personality), intellectual abilities and intelligent behaviour.

\section{Intellectual Abilities, IQ and Intelligent Behaviour}

Intelligence tests, as their name suggests, attempt to measure general intelligence. However, the aspect of intelligence (or the intellectual ability) that is being measured depends greatly on the context in which intelligence tests are developed. For example, the first intelligence test was the Binet-Simon intelligence test, the purpose of which was to make a distinction between children who would benefit from normal schooling and those who would not (Gregory, 2007). Academic achievement was the "intelligent behaviour" that this test and many future ones tried to predict. Years later, investigators realized that intelligence could be used to predict other forms of success in life or useful behaviour. Intelligent behaviour was transformed from academic achievement to life achievement. A review article (Neisser et al., 1996) explored the value of Intellectual Quotient (IQ) and its ability to predict useful behaviour or apply intelligence to situations in the real world. They found that IQ explains one fourth of social status variance and one sixth of income variance, indicating that it can predict these variables (Neisser et al., 1996). Furthermore, this score continued to predict social status and income after the parent's social economic status was controlled for, thus showing the strength of IQ in predicting these variables. Also, a correlation of $r=.54$ with job performance was reported, as well as a correlation of $r$ $=-.17$ between IQ scores and number of juvenile offenses after correcting for social class (Neisser et al., 1996). This review of findings shows that intellectual abilities can serve to predict useful life behaviour.

Intellectual abilities are also important in interpersonal relationships. Ybarra et al. explain that human interactions require the use of many executive functions or intellectual abilities (Ybarra et al., 2008). For example, simply exchanging opinions requires for the people involved in a discussion to pay attention to what other people are saying, keep in memory the answers given, adapt their perspective based on what is being discussed, infer emotions and motivations from other people, and inhibit irrelevant comments and behaviour, amongst others (Ybarra et al., 2008). Even if some of these processes are done automatically, intellectual abilities are required in order to have successful interpersonal interactions. This can be seen as a form of intelligent behaviour or useful life behaviour because, as social animals, most people experience some form of social interaction every day, and most of them strive to succeed in their relationships, fulfill their social needs, and enhance their subjective well-being through these interactions (e.g., Prager \& Buhrmester, 1998). Therefore, it could be concluded that striving for good social relationships and interactions is a form of useful or intelligent behaviour and, as previously explained, intellectual abilities are to some degree necessary in order to display this form of intelligent behaviour.

However, merely scoring high on an IQ test alone does not predict successful relationships. This is also the case for the intelligent behaviours described earlier. Even though previous research on IQ shows that it is capable of predicting useful life behaviour, a great quantity of the variance in these measures is still unexplained. This may be due to the lack of control manifested in previous research. That is, the studies mentioned earlier do not control for external variables that may influence the relationship between intellectual abilities and measures of useful life behaviour. In addition, they cannot determine if (and how) other factors would affect this relationship. This article will attempt to investigate other external variables that might influence the relationship between intellectual abilities and intelligent behaviour.

The review of findings on IQ also shows that it is possible to consider intellectual abilities as being able to predict useful life behaviour in the real world in terms of what could be described as good decision making; after all, a person needs to make a conscious decision if $\mathrm{s} /$ he desires to do his/her best at his/her job, if the person does not want to commit a crime, or if the person wishes to engage in a nourishing relationship with someone. For this reason, it is assumed that useful behaviour requires the capacity to make good decisions, and that good decision making can be seen as a form of intelligent behaviour. For example, it is possible to think of people who are intelligent and yet engage in non-intelligent behaviour such as drunk driving, making careless financial decisions, and 


\section{DECISION MAKING, INTELLIGENCE AND PERSONALITY}

continuously failing in their personal relationships. They score high in intelligence tests, yet their high intelligence is insufficient to predict good decisionmaking or useful behaviour. This emphasizes the necessity to consider other factors that correlate with useful or intelligent behaviour and explore these relationships.

Breakwell (2007) examined individual differences and their ability to predict risk perception and behaviour (which could be considered as a form of intelligent behaviour). She states that certain personality factors (such as openness to experience, extroversion and sensation-seeking), cognitive styles (self-efficacy and locus of control) and beliefs about how the world works influence how people perceive risks, and in turn, how willing they are to engage in risky behaviours. Since every decision involves a risk, Breakwell's review reflects the need to explore how individual differences predict useful behaviour in terms of decision making. The first factor to be considered in this study is personality.

\section{Intelligence and Personality}

The connection between intelligence and personality using the Five Factor Model of personality has been explored by several authors (Ackerman \& Heggestad, 1997; Baker \& Bichsel, 2006; ChamorroPrezumic \& Furnham, 2006; Furnham, Dissou, Sloan, $\&$ Chamorro-Premuzic, 2007). The Five Factor Model of personality (McCrae \& Costa, 1987) describes personality as containing five factors, defined as dimensions of individual differences that consistently show themselves in actions, thoughts and emotions. The five factors are extroversion, neuroticism, openness to experience, conscientiousness and agreeableness. Extroversion is the tendency towards positive feelings, excitement and friendliness. Research on the relationship between this factor and intellectual abilities is mixed, with some studies showing a positive relationship (Ackerman \& Heggestad, 1997; Prezumic \& Furnham, 2006) and others showing a negative relationship (Furnham et al., 2007). Prezumic and Furnham (2006) argue that this relationship depends on the type of test used; if it is a speeded test (highly timed but not severely difficult) extroverts do better, but if it is a power test (untimed but of high difficulty) introverts do better. Neuroticism, another personality factor, is defined as the tendency to experience negative emotions such as anxiety; Research
(Ackerman \& Heggestad, 1997; Furnham et al., 2007) generally agrees that neuroticism has a negative correlation with IQ scores.

Openness to experience is the disposition to pay attention to beauty, abstract ideas, and liberalism. Baker and Bichsel (2006) found that openness to experience correlates with intellectual abilities at different stages of life. Other research has confirmed the positive relationship between intellectual abilities and openness to experience (Ackerman \& Heggestad, 1997; Furnham et al., 2007). Conscientiousness involves self-discipline, achievement-striving, and cautiousness. An extensive meta-analysis showed that conscientiousness has no correlation with measures of general intelligence, but that it does correlate negatively with measures of math and general knowledge (Ackerman \& Heggestad, 1997). Other researchers have found that non-conscientious individuals tend to do better in IQ tests (Furnham et al., 2007). Lastly, agreeableness refers to qualities such as altruism, trust and compliance. The meta-analysis mentioned earlier found no correlation between agreeableness and any measure of intellectual ability (Ackerman \& Heggestad, 1997). In summary, it is generally agreed that extroversion has an existing relationship with intellectual abilities, but its direction appears to depend on the kind of test being used. Openness to experience is generally positively correlated with intellectual abilities, while neuroticism is negatively correlated with IQ. The relationship with conscientiousness is generally negative or non-existent, and the relationship with agreeableness is also nonexistent.

The previous review of articles shows that there is an existing relationship between personality and intellectual abilities. However, there is no way to tell which personality traits allow a person to behave more intelligently (or engage in useful behaviour) as opposed to only score higher on IQ tests. This study will examine the mediating or moderating effect of personality, particularly neuroticism, openness to experience, and conscientiousness, in the relationship between intellectual abilities and intelligent behaviour. The first two traits are predicted to influence useful life behaviour because of their relationship with intellectual abilities. The third trait, conscientiousness, is included in the study because of the nature of the measure of intelligent behaviour, which will be explained in detail further below. 


\section{CÁRDENAS \& STOUT}

\section{Intelligence and Emotional Intelligence}

This study is interested not only in personality as a non-intellective factor, but also in other factors that might predict intelligent behaviour. It is for this reason that the predictive importance of Emotional Intelligence (EI) will be explored. Emotional Intelligence is defined as: "the ability to carry out accurate reasoning about emotions and the ability to use emotions and emotional knowledge to enhance thought" (Mayer, Roberts, \& Barsade, 2008, p. 511). This means that a person high in EI will judge and understand his/her emotions as well as those of others, and use the emotions to obtain what $\mathrm{s} / \mathrm{he}$ needs or wants. EI allows the person to enhance his/her capacity to think clearly by joining emotions and intelligence. Therefore, an individual whose thoughts have been enhanced by EI is capable of thinking better. As a consequence, s/he would translate this enhanced thinking into intelligent behaviour such as success in job performance and good peer relationships, which are examples of useful behaviour. This study will treat EI as a non-intellective ability (highly dependent on intellectual ability) because of its emotional content, even though some will argue that it must be thought of as an intellectual ability (e.g. Barchard \& Hakstian, 2004). In fact, EI and verbal measures of intelligence have a correlation of $r=0.36$, which gives evidence for an existing relationship between intelligence and EI (Mayer et al., 2008).

The inclusion of Emotional Intelligence in this study allows for the exploration of a particular form of intelligent behaviour introduced earlier, that is, the capacity to relate appropriately with people and to have acceptable and satisfying relationships with others. Since reading and understanding other's emotions is an important aspect of relationships, EI should play an important role in human relationships and interactions. A study that observed emotional regulation (an ability encompassed by EI) found that the people who scored high on EI were viewed by their peers as being more interpersonally sensitive, as having more prosocial tendencies, and as having more reciprocal friendships (Lopes, Salovey, Côté, \& Beers, 2005). Another study confirmed that those who score high on the managing emotions scales of EI report higher quality of interpersonal relationships, which was also confirmed by two of the participant's friends (Lopes et al., 2004). Other research reports that children who score high on
EI had better social skills, such as cooperation and self control (Mayer et al., 2008). With adults, research shows that EI correlated positively with relationship well-being (Mayer et al., 2008). This research shows that EI influences human relationships, improving human interactions through a better use of emotions and leading to high quality social interactions, which, as mentioned earlier, is a form of intelligent behaviour.

In terms of work skills, research showed that in an organizational simulation, EI (as measured by perception of emotions in faces) correlated positively with successful problem analysis of managerial issues (Matsumoto, LeRoux, Bernhard, \& Gray, 2004). It is also positively correlated with a consistent rise in work place effectiveness for professionals of diverse occupations (Mayer et al., 2008), showing that EI could be used to predict useful behaviour in the job environment.

In conclusion, research shows that EI is an important predictor of intelligent behaviour or useful life behaviour in terms of good personal relationships and work efficacy and as such, it should be considered as one of the factors measured in this study. It is predicted that intellectual abilities will be positively correlated with EI, which in turn will be positively correlated with intelligent behaviour, acting as either a mediator or a moderator.

\section{Intelligence and Subjective Well-Being}

Subjective well-being (SWB) "is concerned mainly with how and why people experience their lives in a positive way, including both cognitive judgments and affective reactions" (Diener, 1984, p. 542). SWB describes the reasons that lead people to evaluate their lives positively and to experience positive affects. The relationship between SWB and intellectual abilities, as measured by IQ, was examined by Diener and he concluded that intellectual abilities and subjective wellbeing had no relationship. This seemed odd since higher intelligence would lead to more resources, and resources are positively correlated with subjective well-being (Diener, 1984). However, it is likely that behaving intelligently (engaging in a concrete action that requires intelligence) could influence the way a person sees and feels about his/her life, as opposed to only taking an IQ test (without any active behaviour). Therefore, it is possible that intelligent or useful behaviour (and the resources that it brings), and not 


\section{DECISION MAKING, INTELLIGENCE AND PERSONALITY}

intellectual abilities as measured by IQ, has a positive relationship with subjective well-being. It is also feasible that people who feel good about their lives want to maintain this state and therefore continue behaving intelligently.

For example, as mentioned previously, having or maintaining good interpersonal relationships can be seen as a form of intelligent behaviour. It is generally agreed that there is a positive relationship between social contact and SWB, even though the variables that affect this relationship are unknown (e.g., Diener, 1984; Gallagher \& Vella-Brodick, 2008). This positive relationship would indicate that either behaving intelligently and having good relationships with others increases SWB, or that having a high SWB allows for better relationships with others. For this reason this non-intellective factor will be examined in this study.

\section{Prospect Theory and Good Decision-Making}

Wechsler (1975) regarded goal awareness as an important part of intelligence, emphasizing that general intelligence would necessarily involve a person's capacity to assess the worthiness and excellence of a goal and a behaviour. This would mean that people who behave intelligently, do so because they are capable of assessing and judging goals and behaviours based on their worth. Thus they are able to choose the best option, according to their subjective point of view. Intelligent behaviour or useful behaviour would require the person to be somewhat conscious of the choice of behaviours that can be displayed, as well as of the consequences of these choices. After being conscious of choices and consequences, the person selects the best option, according his/her personal situation. For example, in interpersonal relationships, a person having a discussion needs to be conscious that during the discussion $\mathrm{s} / \mathrm{he}$ can choose to say something that will either help or hinder the argument. In other words, $\mathrm{s}$ /he knows that there is a preferable (or more useful) behaviour. This knowledge and the capacity to carry out appropriate actions depend on individual differences, such as personality factors. If the person has the knowledge and chooses to make a hurtful comment during a discussion, the situation will likely be worsened, even if $\mathrm{s} /$ he does not know exactly how. This means that the person is somewhat conscious of the consequences of his or her actions, even if the individual does not know the full consequence of his or her behaviour. In this example, a form of intelligent behaviour would be to choose to say something that would help during the discussion.

The Expected Utility Model states that a "rational decision maker will prefer the prospect that offers the highest expect[ed] utility" (Tversky \& Kahneman, 1981, p. 453), meaning that an intelligent person would be capable of always choosing the option that represents the greatest benefit to him or her. Yet, this model is unable to predict decision making under uncertain circumstances (Kahneman \& Tversky, 1979), showing that people take the context into consideration when making a decision.

Due to the Expected Utility Model's inability to predict decision making under uncertainty, Tversky and Kahneman established Prospect Theory, which explores the biases, heuristics, rationality and irrationality of decision-making (1979). Since choices made under risky circumstances heighten the idea of what is most practical or beneficial, the introduction of Prospect Theory allows us to see intelligent behaviour reflected in decision making under risky situations, which serves as the dependent measure.

Research on Prospect Theory has found typical ways in which people respond to decisions under uncertainty. One of the most interesting findings is the framing effect which states that the framing of situations, acts, and contingencies is capable of making a person change his decision on what to do (Kahneman \& Tversky, 1979). In other words, people become inconsistent in their choices if someone simply words or frames parts of a problem differently. For example, Tversky and Kahneman (1981) presented a situation to one group of participants. They were told that they were going to buy a theater ticket for $\$ 10$, only to discover that they had lost the $\$ 10$ bill. They were then asked if they would still buy the ticket. Another group of participants was given the same situation, but instead of having lost the $\$ 10$ bill, they had lost the ticket itself. They were then asked if they would buy another ticket. Even though they were under the same circumstances (they both had lost something worth $\$ 10)$, more people were willing to buy a ticket in situation one than in situation two. Even though the two situations were the same, the two groups reacted differently to each frame. However, it is postulated that if a person with certain personal characteristics (such as scoring high on IQ tests) answers both questions, $\mathrm{s} /$ he would be able to resist the frame and see the two 


\section{CÁRDENAS \& STOUT}

questions as the same, thus being consistent in his or her answers.

Tversky and Kahneman (1981, p. 453) explained that "the frame that is adopted is controlled partly by the formulation of the problem and partly by norms, habits, and personal characteristics of the decision maker", stating that personal characteristics are significant determinants of how the frame of a problem affects a person. However, most research on Prospect Theory tests the formulation or framing of the problems and how it affects decision making. In fact, past research and experiments concentrated on creating questions that changed the framing of problems, thus studying the inconsistency in choices (for studies in this area see Larrick \& Blount, 1997; Tversky \& Kahneman, 1981; Tversky \& Kahneman 1991; Winter \& Parker, 2007). When studying this phenomenon, experiments generally obtained samples from every part of the distribution, ignoring individual and personal characteristics that may influence the frame taken by a person. The purpose of this study is to investigate the personal characteristics that may control the frame that a person adopts. More specifically, this study will explore the relationship between intellectual abilities and such decision-making problems, and how non-intellective factors may influence the frame adopted.

Jones, Frisch, Yurak, and Kim (1998) explain that the findings of Prospect Theory (particularly the importance of framing situations and consequences) are a thorough investigation of people's irrationality when making decisions. They explain that Prospect Theory reveals how controlled people are by the circumstances and situations in everyday life. However, there is no reference to those who are capable of resisting the frame, and that they may do so because they hold an underlying principle that guides their choices. After all, in the example with the theatre tickets, there were some participants who decided to buy the ticket again even if they had lost one already. Each person's underlying principle gives him/her a reason for behaving as he or she does, and it involves values, ideas of what is right and wrong, and priorities to be kept. A guiding principle could allow people to be rational and consistent in their decision-making process. This rationality is hypothesized to require more than intellectual abilities, and it involves nonintellective factors, which is the reason why nonintellective factors are included in this study (personality, EI, and SWB). The present article will examine the way in which intelligent behaviour, reflected in decision making, is influenced by intellectual abilities, personality, EI and subjective well-being.

\section{Hypotheses}

It is hypothesized that intellectual abilities are related to intelligent or useful behaviour (which in this case is decision making) because behaving intelligently requires the person to use intellectual abilities such as logic and memory. Since general intelligence involves the capacity to act purposefully (Wechsler, 1975), and IQ tests attempt to measure general intelligence, it is theorized that those who score high on intellectual abilities tests are more likely to have a purpose for answering as they do, and thus answer consistently. Therefore a positive relationship between the intellectual ability test and the decision-making measures is expected. It is believed that EI will have a positive effect on decision making: if emotions are purposeful and Emotional Intelligence leads a person to use emotions to their maximum utility, then higher EI would allow a person to make consistent decisions by enhancing their capacity to think rationally and therefore reducing the influence of the frame. For this reason EI was included as a factor to predict intelligent behaviour. A measure of subjective well-being was also included because no previous study has explored the relationship between feeling good about one's life and making good decisions. It is possible that those who have made intelligent decisions before have higher life satisfaction, which in turn would drive them to continue to make good decisions.

Previous research has shown that openness to experience correlates with measures of intellectual abilities; therefore, it is hypothesized that in this study it will be positively correlated with intellectual abilities. Openness to experience will also be positively correlated with decision-making since a person with this personality trait might have the ability to look beyond the frame and be able to resist it. The relationship between decision-making and neuroticism is expected to be negative since anxious people should have a greater difficulty answering consistently and resisting the frame if the question is capable of altering their emotions greatly (Chamorro-Premuzic \& Furnham, 2006). Conscientiousness was included in 


\section{DECISION MAKING, INTELLIGENCE AND PERSONALITY}

this study as a predictor of good decision making in spite of the lack of relationship with IQ because of the nature of the decision-making task. Since conscientious people cautiously consider their options before making any decision, it could make them better decision makers. Therefore, it is predicted that it will correlate positively with the decision-making task.

In summary, it is hypothesized that there will be a positive correlation between intellectual factors, subjective well-being, Emotional Intelligence, openness to experience, and conscientiousness with good decision making. A negative relationship between neuroticism and decision making is expected. In order to see the hypothesized path diagram, refer to Figure 1.

\section{Method}

\section{Participants}

Ninety-seven participants ( 85 were current students at Bishop's University), volunteered to participate in this study. All participants were aged 18 or older $(28$ male and 69 females). They participated in a draw for four $\$ 10$ gift certificates and those taking a psychology class could earn 1.5 bonus points towards most psychology classes. Of the 97 participants, two participants' data was removed due to low English language proficiency levels.

\section{Materials}

Several psychometric tests were employed in this study. The Wonderlic Personnel Test (WPT) was used in order to measure intellectual abilities. This test has been shown to have high test-retest reliability at $r=.94$ (Dodrill, 1983) with a time delay of 5.28 years average, an internal consistency of $r=.88$ (Wonderlic, 1983), and a high predictability of the Wechsler Adult Intelligence Scale (WAIS) scores, with correlations ranging from .91 and .93 (Dodrill, 1981). This is a highly timed test (12 minutes) containing 50 items. Participants had to answer as many items as possible in this time frame. The final score is achieved by subtracting the number of wrong answers from the total number of questions answered.

As a personality measure, the IPIP-NEO short

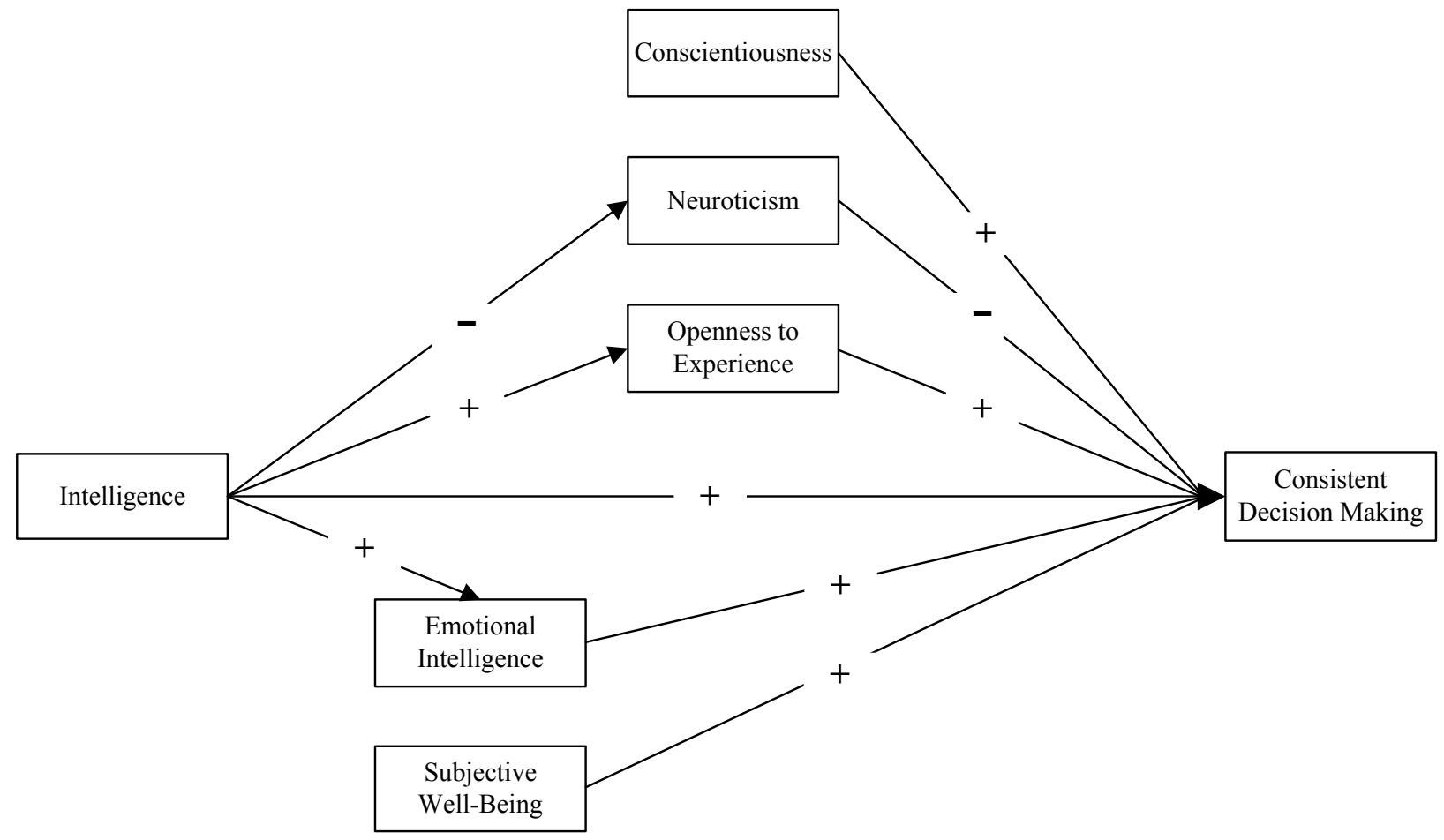

Figure 1. Hypothesized path analysis diagram: the relationship between intelligence and consistent decision making is mediated or moderated by personality and emotional intelligence. Subjective well-being has a direct relationship with consistent decision making. 


\section{CÁRDENAS \& STOUT}

version was employed. This test is a free, online, research-based test that is accessible to anyone doing research. The test measures personality in terms of the well-established five traits, extroversion, openness to experience, neuroticism, agreeableness and conscientiousness and it contains 120 items. The answers indicate how much a subject agrees with the statement as it applies to him or her and are in multiple-choice format ranging from "very inaccurate" to "very accurate". This test revealed a total of five scores, one for every personality factor. The higher the score the more the person displayed the trait. This test has an alpha coefficient of .84 (International Personality Item Pool, 2008). As evidence of validity, Goldberg reports that compared to other personality tests (such as the NEO Personality Inventory) the IPIPNEO was the best predictor of risk avoidance and total health related practices (Goldberg, 1999); also the scales of the IPI-NEO have a $r=.73$ correlation with the scales of the NEO Personality Inventory.

In order to measure decision making, a decisionmaking task was created based on several designs or questions written by Kahneman and Tversky (1981, 1991), Winter and Parker (2007), and Larrick and Blount (1997). A study on the effectiveness of the framing effect found that the most effective designs or questions for producing a framing effect are those that deal with an Asian disease, gambling, or tax evasion (Kühberg, 1998). Accordingly, the designs or items of the dependent variable were chosen in accordance with their effectiveness at producing the framing effect. However, not all designs could be translated into a pencil and paper exam because their nature required group interaction. Therefore, it was attempted to choose effective and easily-performed designs that could be executed by a single subject with answers that could be written easily. Consequently, 6 designs were used. Each design contained 2 frames of the same problem framed differently, which led to a total of 12 items. For an example of the items, see Appendix 1.

When the participant answered consistently to both frames, that is, the same design formulated differently, $\mathrm{s} /$ he received one point. When the individual did not answer consistently, that is, when the participant responded differently to both frames, s/he received no points. The maximum score revealing perfect consistency is 6 while the minimum score revealing no consistency is 0 . The items were chosen so that there would not be one right answer and in this way avoid judging why a person thought that one decision was better than another one, and whether this judgment was correct or not. It is for this reason that consistency in decisions is the scoring method.

In order to measure Emotional Intelligence the Levels of Emotional Awareness (LEAS) was used. The test contains social situations involving two characters, the person reading the test and another other person. All scenes elicit an emotional response and the participant must answer how the two people involved in the situation would feel. The short version, which contains 10 items, was used due to time restraint. The answer to each scenario is rated from 0 to 5 based on the emotional depth revealed in the answer, which adds up to a total maximum score of 50 in the short version. The scoring of the items is based on the LEAS manual (Lane, 1991). Myers et al. (2008) report that it possesses an alpha coefficient ranging between .81 to .89. Lane et al. (1990) correlated the total score of the LEAS with the Washington University Completion Sentence Test (SCT), a measure of psychological maturity, and the Parental Description Scale, which measures the level of complexity in the representations of others. The authors found a significant positive correlation with both tests, indicating that those who have higher levels of maturity and those who understand the complexity found in other people tend to score higher on the LEAS. For an example of an item of the LEAS see Appendix 2.

The General Well Being Scale or Schedule (GWB) was used to assess subjective well-being. This test contains 18 items, and there are six possible answers for each question ranging from 0 (all the time) to 5 (none of the time); the participants answered in accordance to how they had been feeling over the past month. Only items 15 to 18 have scores that range from 0 to 10. The test taps into different aspects of well-being such as depression, positive emotions, and satisfaction with personal relationships. The participants are asked to choose the answer that reflects best how they had been feeling for the past months. To score the GWB, the numbers chosen by the participants in each of the 18 items are added in order to give a global score that ranges from 0 to 110 points, where larger scores indicate greater well-being. Internal consistency for the GWB ranges from .90 to .94 and test-retest reliability ranging from .68 to .85 . 


\section{DECISION MAKING, INTELLIGENCE AND PERSONALITY}

\section{Procedure}

Most participants were tested in either the psychology lab or the library, and while some others had the option to participate in their homes. Participants filled out the consent form and took the tests and scales in a counterbalanced order. In order to avoid fatigue, subjects had the choice of taking a five minute break after every two tests, allowing for two breaks and three testing periods. The intelligence tests (WPT and EI) were given first in order to avoid the effect of the subjects' fatigue on the intelligence tests. It is for this same reason that the decision-making task was taken alone in the second session. In the last block the LEAS and the GWB were given. To minimize the effect of order, the order of the tests within each period was counterbalanced, giving a total of four counterbalancing conditions. Then the debriefing form was given.

\section{Results}

To test the path analysis, a standard multiple regression was performed between the predictors (intellectual abilities, personality factors, EI, and subjective well-being), and the decision-making task. If any of the predictors act as a mediator, there should be a direct relationship (a significant correlation) between intellectual abilities and the decision-making task, as well as a significant relationship between the mediator variable, the intellectual abilities test and the dependent variable. Also, the correlation between the test of intellectual abilities and the decision-making task would be smaller when the predictor is removed from
Table 1.

Means of the Decision Making Task, Standard Deviations and Number of Participants for Each Counterbalancing Condition

\begin{tabular}{cccc}
\hline Condition & $n$ & $M$ & $S D$ \\
\hline 1 & 25 & 4.48 & 0.23 \\
2 & 23 & 4.32 & 0.25 \\
3 & 24 & 4.50 & 0.24 \\
4 & 23 & 4.60 & 0.24 \\
\hline
\end{tabular}

the equation (by partialling out the variable) (Keith, 2006). If any of the variables act as a moderator, it would change the nature of the relationship between different intellectual abilities' scores and decision making (sometimes it would be positive and some others negative). To test for moderation, the variable was included and removed by partialling the possible moderator, and the results were observed in the correlation value (Keith, 2006).

A one-way ANOVA was carried out over the four counterbalancing conditions in order to compare their decision-making means score, and see whether there was any effect due to test order. The ANOVA revealed no significant mean difference, with an $\mathrm{F}$ value for condition of $F(3,90)=.24, p=.88$. See Table 1 for means of decision making, standard deviations and number of participants in each counterbalancing condition.

Table 2.

Correlations Between Intellectual Abilities, EI, SWB, Personality Factors and Decision Making

\begin{tabular}{|c|c|c|c|c|c|c|c|c|c|}
\hline & 1 & 2 & 3 & 4 & 5 & 6 & 7 & 8 & 9 \\
\hline 1. WPTscore & -- & .17 & .08 & .18 & -.05 & .10 & -.03 & .01 & .15 \\
\hline 2. LEASscore & & -- & -.01 & .10 & .16 & -.03 & $.21 *$ & .04 & -.11 \\
\hline 3. GWB & & & -- & -.21 & $-.37 * *$ & .12 & -.04 & .20 & -.07 \\
\hline 4. Openness & & & & -- & -.10 & $.24 *$ & .17 & .09 & .13 \\
\hline 5. Neuroticism & & & & & -- & -.20 & -.07 & $-.25 *$ & .06 \\
\hline 6. Extraversion & & & & & & -- & .03 & .08 & .04 \\
\hline 7. Agreeableness & & & & & & & -- & $.45^{* *}$ & -.03 \\
\hline 8. Conscientiousness & & & & & & & & -- & .08 \\
\hline 9. Decision Making & & & & & & & & & -- \\
\hline
\end{tabular}




\section{CÁRDENAS \& STOUT}

A regression was performed between the number of consistent responses on the decision-making task (the dependent variable), and intellectual abilities, the five personality scores, EI and subjective well-being. Table 2 shows the intercorrelations between these variables and Table 3 shows means, standard deviations and number of participants for each variable. All the correlations were run at an alpha level of .05. If personality, subjective well-being or emotional intelligence mediated the relationship between intelligence and decision making, a significant correlation between intellectual abilities and decision making would be expected. However, the results reveal that there was no significant relationship between the WPT (intellectual abilities test) and the decisionmaking task. Furthermore, the correlation between Emotional Intelligence and decision-making was found to be non-significant, as was the relationship between EI and intellectual ability. There was no significant correlation between the decision-making task and the subjective well-being measure (GWB). The relationship between decision making and the hypothesized personality factors, namely openness to experience, neuroticism, and conscientiousness was non-significant; the same is true of the relationship between the intellectual abilities (WPT) and the two hypothesized mediating personality factors, openness to experience and neuroticism. Tolerance is a collinearity statistic that indicates the degree to which each variable is independent from or orthogonal to the other variables in a regression analysis. A tolerance score of 1 indicates total independence and a score of 0 indicates entire dependence. If any of the variables was acting as a moderator, it would have a low tolerance level when correlated with the predictor, indicating the

Table 3.

Means, Standard Deviations and Number of Participants for All Variables

\begin{tabular}{lccc}
\hline & $N$ & $M$ & $S D$ \\
\hline WPT score & 95 & 24.52 & 5.95 \\
LEAS score & 95 & 32.50 & 4.38 \\
GWB & 95 & 74.06 & 14.97 \\
Openness & 93 & 84.05 & 9.90 \\
Neuroticism & 93 & 65.43 & 10.22 \\
Extraversion & 93 & 83.00 & 12.03 \\
Agreeableness & 93 & 91.08 & 10.27 \\
Conscientiousness & 92 & 86.48 & 9.86 \\
Decision making & 94 & 4.48 & 1.15 \\
\hline
\end{tabular}

Table 4.

Tolerance Value for Every Scale

\begin{tabular}{lc}
\hline Variable & Tolerance \\
\hline WPT & 0.88 \\
Openness & 0.86 \\
Conscientiousness & 0.75 \\
Agreeableness & 0.76 \\
Extraversion & 0.91 \\
Neuroticism & 0.81 \\
GWB & 0.78 \\
LEAS & 0.90 \\
\hline
\end{tabular}

shared variance. Results indicate that all of the variables have high tolerance, ranging from .93 for the WPT scores to .73 for conscientiousness. To see all the tolerance values refer to Table 4 .

In order to see if there were any hidden effects, each of the hypothesized mediating variables was partialled out (EI, openness to experience, neuroticism, and conscientiousness) as the WPT scores were correlated with decision making. When controlling for EI, the correlation between the decision-making task and WPT approached significance, $\mathrm{r}(90)=.19, \mathrm{p}=.07$. When partialling out openness, the correlation between decision making and the Wonderlic showed almost no change, $\mathrm{r}(89)=.15, \mathrm{p}=0.16$. Finally, when controlling for neuroticism, the relationship between WTP and decision-making came closer to significance, $\mathrm{r}(89)=.17, \mathrm{p}=.11$. However, none of the results were statistically significant.

\section{Discussion}

The ANOVA analysis showed that the order in which tests are given does not affect the results. With this assumption met, the other results can be interpreted. It was hypothesized that the scores of the intellectual ability test would positively correlate with the decision-making task. However, no significant correlation was found. Nonetheless, this correlation was the closest to significance compared to the other variables hypothesized to correlate with decision making. It was also hypothesized that openness to experience and conscientiousness would positively correlate with the decision-making task, while neuroticism would negatively correlate with the 


\section{DECISION MAKING, INTELLIGENCE AND PERSONALITY}

dependent variable. However, no significant correlation was found. EI was hypothesized to correlate positively with decision making but a negative nonsignificant correlation was found. Also, there was no significant correlation between subjective well-being and the decision-making task nor with the WPT. In the latter case, Diener's (1984) results were replicated.

Observing the lack of significance in all correlations, it could be concluded that there is no mediating effect between decision making and the intelligence measures, since mediation would require the mediating factors to correlate with decision making and with intellectual abilities. Also, the high tolerance value of every factor indicates that no mediation or moderation occurs because every factor is independent from each other. Additionally, the lack of moderation can be seen in that none of the variables are significantly or negatively correlated to begin with. However, when EI was controlled for, the correlation between intellectual abilities and decision making increased, approaching significance. This would indicate a possible moderating effect of EI in the relationship between intellectual abilities and decision making.

Understanding the results can be simplified by stating that there is no significant relationship between intelligence and personality in the prediction of intelligent behaviour, and that intellectual abilities do not necessarily predict how consistently a person makes decisions. Nevertheless, this would be oversimplifying the results. Although the relationship between intellectual abilities and decision making is not significant, its correlation is the highest of those that were predicted to correlate with decision making ( $r$ $=.15$ ), which indicates that there is a positive trend in this direction. Also, one of the three personality variables that were hypothesized to be related to decision making, namely openness, had higher correlations than the other personality factors with decision making $(r=.12)$. Lastly, there seems to be a moderating effect of EI on how intellectual abilities relate to decision making since this correlation approached significance when EI was partialled out. These findings imply that maybe this study did not have enough participants or enough variability in participants to obtain significance in the correlations. Ackerman and Heggestad (1997) pointed out that openness to experience positively correlates with intellectual asbilities. However, in the present study, no such relationship was found, which gives evidence that there may have been a restriction of range due to the homogenous sample of undergraduate students.

Gallagher and Vella-Brodick (2008) reported a high correlation between Emotional Intelligence and subjective well-being, while Mayer et al. (2008) reported a positive relationship between EI and intellectual abilities. However, this study found no significant correlation in either case. This may be another indicator of the restriction of the sample. Unfortunately, most of the participants were university students, who are very similar to each other in age, intellectual abilities, and in certain personality traits. Therefore, it could be concluded that homogenous sampling might have influenced the results of the study, lowering variance and thus the correlation between variables.

An additional problem with this study is the fact that Bishop's University has a great number of international students as well as French-speaking students. This is a problem particularly for the Wonderlic Personnel Test because it is a test that measures intellectual abilities and as such, some of the questions are culture and language bound; this means that only those who are Anglophone and have grown up in this culture would know the answer whereas people who do not know native English expressions had a lower score than they would have had in another intellectual abilities test; their intellectual ability score in the WPT may not reflect their real intellectual ability score. Another criticism regarding the choice of intelligence test is the nature of the test. As mentioned in the introduction, individuals who score high on the extroversion trait score higher in highly speeded tests, while introverts tend to score lower on these kinds of tests (Chamorro-Prezumic \& Furnham, 2006). This is because extroverts trade speed for accuracy when solving cognitive problems, while introverts are more concerned with accuracy (Chamorro-Prezumic \& Furnham, 2006). The WPT is a timed test where the participant has 12 minutes to answer as many questions as possible. This favors extroverts and hinders introverts, which could mean that unfortunately an introvert's score on the WPT might be lower than his/her true intelligence score.

The other criticism refers to the dependent variable. By making it a decision-making task, this study explored how people make decisions, as well as the 


\section{CÁRDENAS \& STOUT}

personal variables that affect their choices. Additionally, the decision-making task was testing the notion that people make choices partly based on their guiding values, motivations and cognitions. Those that have certain personal factors (e.g. being high on conscientiousness), and who also possess a guiding principle would be more likely to make the same decision when a problem was presented under different frames (thus being faithful to their guiding principles) than those possessing a guiding principle but not having the personal factors (e.g. being low on conscientiousness). Also, if a person has the personal factors (e.g. being high on conscientiousness) but has no underlying principle to explain his/her choice, it was assumed that the frame or situation would have a greater effect on $\mathrm{him} / \mathrm{her}$. Yet, at no point were participants asked about their reasons for choosing one option over another. This was done in order to avoid judging their rationale, and because it would be hard to distinguish situational reasons (caused by the frame) from personal reasons (such as values). However, without this information it is hard to know whether the dependent variable was actually measuring if people with a guiding principle could resist the frame. Since most questions were presented as possessing dichotomous answers, it is not possible to know the reason why the participants made the decisions they did and if they chose based on a guiding principle. It is hard to know the exact reason why people choose as they do, and at times it might seem that they are behaving inconsistently, but this is only because their underlying principles are unknown to outside observers. In this way, the dependent measure might not have been ideal for measuring consistency according to values because the underlying principles themselves were not being tested.

Another assumption in the decision-making task is that the reactions to decisions made on a piece of paper are similar to those faced in real life. However, this assumption may not be correct; imagining oneself in a situation is not the same as actually being in the situation. For example, one of the items asks participants to imagine that they were in a car accident and they are losing and regaining consciousness repeatedly. The doctor tells them that there is a $40 \%$ chance that they will fall into a deep coma, and if this is the case, asks whether they would want to use life support or not. Even though this question in itself can arouse emotions similar to those that would be felt under the particular circumstance, the intensity of these emotions would not be the same. The decision the participants make in this problem does not represent a big loss (death) because in reality participants are not in that situation. Since the nature of the task is a paper exam, it may not accurately represent real life situations. For example, if a participant is asked how s/he would react when having a discussion with someone, his/her answer in the test might be very different from how $\mathrm{s} /$ he would react when in a real life social interaction. This means that the decisionmaking task may not possess ecological validity.

An additional criticism about the dependent variable is that it contained 12 items, or a total of 6 designs and a maximum score of 6 . Yet, 90 of the 95 participants scored 3 or more. This has two meanings. One meaning is that the dependent variable did not have enough variance in itself to catch the variability in subjects, or in other words, it had restriction of range. If more items had been included, there would have been more variance which would allow us to see a stronger relationship between the predicted factors and participants' consistency. The other issue that arises with having a high "low" score is that it could mean that many people are capable of resisting the frame when faced with the same situation formulated differently. This would indicate that most people have an underlying reason for choosing as they do and it is possible that many of the changes in preference found in Prospect Theory research would not exist if more within-subjects experiments were performed. Nonetheless, Kühberger (1998), in his meta-analysis on Prospect Theory, describes that the least frequently used within-subjects design had stronger framing effects than the most common between- subjects comparison. This effect was not replicated, as described above. Nevertheless, a replication could have existed if there had been two testing sessions separated by a somewhat lengthy time period, and if a different frame to each problem was presented at every session. In this way, participants would have vaguer memories about the items and their content than if they answered all items at the same time. Testing participants at two different times would allow the researcher to distinguish between the effects of memory and acting (or not acting) upon values in resisting the frame and choosing consistently.

Future research should try to improve on the methodological problems described above since it will more likely reveal the real relationship between good 


\section{DECISION MAKING, INTELLIGENCE AND PERSONALITY}

decision making and intelligence, and if there is any personality factor(s) influencing this relationship. For example, a more heterogeneous sample should be tested, preferably sampling people from outside the university context, since this would increase the variance in the data. It would also allow any finding to be generalized to the general population. In addition, the tests used should be compatible with the culture being tested, particularly for the intelligence tests, since they usually examine some form of general knowledge. However, this "general knowledge" can change from one culture to another. Therefore it is important to make sure that the test is appropriate for the culture of the sample being tested. In addition, future studies should use intelligence tests that combine power and speed in an equal manner, and in this way give equal opportunities to both extroverts and introverts.

Future research could also improve the decisionmaking measure and increase its ecological validity by making the decisions more similar to what happens outside the laboratory. This could be done by asking participants to enact the decision that needs to be made. This method could not be used in all the items and it would take considerably more time. However, it is proposed that it would increase the validity of the decision-making task because the mental state of the participants when being tested would be more similar to their state of mind when taking decisions in the real world. It would also be interesting to ask participants the reason why they chose as they did, and if there is any underlying value that explains their consistency (or lack of consistency). Finally, to address whether participants are truly consistent or if it is only the effect of memory, a within-subjects study with participants taking the decision-making task at two times is ideal. Half of the items would be given at one time, and the other items (those given at time one but framed differently) would be given in time two.

In conclusion, this study aimed at understanding the relationship between intellectual abilities and nonintellectual factors. A review of previous research had shown that intellectual abilities are not enough to explain useful life behaviour, and it was hypothesized that certain non-intellective factors (such as openness to experience) would make this relationship stronger. The study examined Wechsler's statement that intelligence goes beyond the use of intellectual abilities as measured by IQ tests and that a certain personality and motivation is important in order to really be intelligent. Although the current study did not have significant results, it paved the way for different ways of measuring useful life behaviour. Furthermore, it was unique in trying to explain the relationship between intellectual factors, non-intellectual factors and useful life behaviour using path analysis and examining the interaction between these factors. It also opens the possibility of conceiving of human interrelationship as a form of intelligent behaviour. Even though research generally agrees that having good relationships with others is important, it has never been considered as an activity that requires both intellectual and nonintellectual abilities in order to produce benefit.

Cattell (1987, p. 13) once expressed that "a thing is a unity when its parts move together, change together, and respond together to some treatment or stimulation". Following this quote, it could be said that even though a person is composed of several parts such as two arms, two legs and one brain, this person is not counted as the sum of his or her parts but as a person, as a unity. The same is the case with human nature. Even though it is composed of intellectual abilities, personality, emotional intelligence and subjective well-being, when describing these parts in respect to ourselves we begin with the word "I", indicating that this pronoun is the essence that holds all other variables together. For this reason, it seems important to consider and remind ourselves that in order to understand ourselves, this "I" only known by each individual must be looked at globally and not just as separate parts.

\section{References}

Ackerman, P. L., \& Heggestad, E. (1997). Intelligence, personality and interests: Evidence for overlapping traits. Psychological Bulletin, 121, 219-245.

Baker, T. J., \& Bichsel, J. (2006). Personality predictors of intelligence: Differences between young and cognitively healthy older adults. Personality and Individual Differences, 41, 861871.

Barchard K. A., \& Hakstian, R. A. (2004). The nature and measurement of emotional intelligence abilities: Basic dimensions and their relationships with other cognitive ability and personality variables. Educational and Psychological Measurement, 64, 437-462. 


\section{CÁRDENAS \& STOUT}

Breakwell, G. M. (2007). The psychology of risk. New York, NY: Cambridge University Press.

Cattell, R. B (1987). Intelligence: its structure, growth and action. New York, NY: Elsevier.

Chamorro-Premuzic, T., \& Furnham, A. (2006). Intellectual competence and the intelligent personality: A third way in differential psychology. Review of General Psychology, 10, 251-267.

Diener, E. (1984). Subjective well-being. Psychological Bulletin, 95, 542-575.

Dodrill, C. B. (1981). An economical method for the evaluation of general intelligence in adults. Journal of Consulting and Clinical Psychology, 49, 668673.

Dodrill, C. B. (1983). Long term reliability of the Wonderlic Personel Test. Journal of Consulting and Clinical Psychology, 51, 316-317.

Furnham, A., Dissou, G., Sloan, P., \& ChamorroPremuzic, T. (2007). Approaches to learning and the acquisition of general knowledge. Individual Differences, 43, 1563-1571.

Gallagher, E. N., \& Vella-Brodick, D. A. (2008) Social support and emotional intelligence as predictors of subjective well-being. Personality and Individual Differences, 44, 1551-1561.

Goldberg, L. R. (1999). A broad-bandwidth, publicdomain, personality inventory measuring the lowerlevel facets of several five factor models. In I. Mervielde, I. Deary, F. De Fruyt, \& F. Ostendorf (Eds.), Personality Psychology in Europe, Vol. 7 (pp. 7-28). Tilburg, The Netherlands: Tilburg University Press.

Goldberg, L. R. (2008). International personality item pool: A scientific collaboratory for the development of advanced measures of personality and other individual differences. http://ipip.ori.org/newBigFive5broadTable.htm.

Gregory, R. J. (2007). Psychological testing: History, principles and applications. $5^{\text {th }}$ ed. Boston, MA: Allyn and Bacon.

International Personality Item Pool. (2008). Retrieved from http://ipip.ori.org/

Jervis, R. (2004). The implications of prospect theory for human nature and values. Political Psychology, $25,163-176$.

Jones, S. K., Frisch, D., Yurak, T.J., \& Kim, E. (1998). Choices and opportunities: another effect of framing on decisions. Journal of Behavioural Decision Making, 11, 211-226.

Kahnmena D., \& Tversky, A. (1979). Prospect theory: An analysis of decision under risk. Econometrica, 47, 263-292.
Keith, T. (2006). Multiple Regression and beyond. Boston, MA: Allynb and Bacon.

Kühberger, A. (1998). The influence of framing on risky decisions: A meta-analysis. Organizational Behaviour and Human Decision Processes, 75, 2355.

Lane, R. (1991). LEAS scoring manual and glossary. Tucson, AZ : University of Arizona

Lane, R. D., Quinlan, D. M., Shwartz, G. E., Walker, P. A., \& Zeitlin, S. B. (1990). The levels of emotional awareness scale: A cognitivedevelopmental measure of emotion. Journal of Personality Assessment, 55, 124-134.

Larrick, R. P., \& Blount, S. (1997). The claiming effect: Why players are more generous in social dilemmas than in ultimatum games. Journal of Personality and Social Psychology, 72, 810-825.

Lopes, P. N., Brackett, M. A., Nezleck, J. B., Schütz, A., Sellin, I., \& Salovery, P. (2004). Emotional intelligence and social interaction. Personality and Social Psychology Bulletin, 30, 1018-1034.

Lopes, P. N., Salovey, P., Côté, S., \& Beers, M. (2005). Emotion regulation abilities and the quality of social interaction. Emotion, 5, 113-118.

Matsumoto D., LeRoux, J. A., Bernhard, R., \& Gray, H. (2004). Unravelling the psychological correlates of intercultural adjustment potential. International Journal of Intercultural Relations, 28, 281-309.

Mayer, J. D., Roberts, R. D., \& Barsade S. G. (2008). Human abilities: Emotional intelligence. Annual Review of psychology, 59, 507-536.

McCrae, R. R., \& Costa, P. T. (1987). Validation of the five-factor model of personality across instruments and observers. Journal of Personality and Social Psychology, 52, 81-90.

Neisser, U., Boodoo, G., Bocuahd, T. J. J., Boykin, A. W., Brody, N., Ceci, S. J., ... Urbina, S. (1996). Intelligence: Knowns and unknowns. American Psychologist, 51, 77-108.

Prager, K., J., \& Buhrmester (1998). Intimacy and need fulfillment in couple relationships. Journal of Social and Personal Relationships, 15, 435-469.

Tversky, A., \& Kahneman, D. (1981). The framing of decisions and the psychology of choice. Science, $211,453-458$.

Tversky, A., \& Kahneman, D. (1991). Loss aversion in riskless choices: A reference dependent model. Quarterly Journal of Economic, 106, 1039-1061.

Wechsler, D. (1975). Intelligence defined and undefined: A relativistic appraisal. American Psychologists, 30, 135-139. 


\section{DECISION MAKING, INTELLIGENCE AND PERSONALITY}

Winter, L., \& Parker, B. (2007). Current health and preferences for life-prolonging treatments: An application of prospect theory to end-of-life decision making. Social Sciences and Medicine, 65, 1695-1707.

Wonderlic, E. F. (1983). Wonderlic Personnel Test. Northfield, IL: Wonderlic \& Associates, Inc.

Ybarra, O., Burnstein, E., Winkielman, P., Keller, M. C., Manis, M., Chan, E., \& Rodriguez, J. (2008). Mental exercising through simple socializing: Social interaction promotes general cognitive functioning. Personality and Social Psychology Bulletin, 34, 248-259.

Zachary, R. A. (1990). Wechsler's intelligence scales: Theoretical and practical considerations. Journal of Psychoeducational Assessment, 8, 276-289.

\section{Appendix 1}

\section{Example of an Item of the Decision Making Measure}

These two problems are two ways of framing differently the same design. They were two items of the dependent variable.

\section{Problem A}

Imagine that you are in an experiment and you were randomly paired with another student to participate in a resource-distribution task. Also imagine that there is a pool of $\$ 7.00$ made available by the experimenter. Each student was randomly assigned to the role of either Player 1 or Player 2. Player 1 will be asked to propose a division of $\$ 7.00$ between the two players, such that \$X for Player 1 and $\$ 7-X$ for Player 2. Then, Player 2 will be asked whether he or she accepts or rejects this proposal. If Player 2 accepts the proposal, each player will get the amount Player 1 proposed. If Player 2 rejects the proposal, neither student will receive any money.

Imagine that you are Player 2. Player 1 has already divided the $\$ 7$ in such way that Player 1 receives $\$ 5.50$ and Player 2 receives $\$ 7-\$ 5.50=\$ 1.50$. You can either decline the proposition and each Player will receive $\$ 0$, or you can accept the proposition and receive $\$ 1.50$.

What would you do?

Accept the proposition

Decline the proposition

\section{Problem B}

Imagine that you arrive to class and your teacher announces that all student have to participate in an exercise that will reveal how students distribute money amongst themselves. You were randomly paired with another student and the teacher announces that there is a pool of $\$ 10.00$ made available for every pair of students. Each student was randomly assigned to the role of either Player 1 or Player 2. The teacher explains that Player 1 will be asked to state a claim for some portion of $\$ 10.00$, such as $\$ X$. Then, knowing $\$ X$, Player 2 will be asked to state his or her claim for some portion of $\$ 10.00$, let's say $\$ Y$. If the total of the two claims $(\$ X+\$ Y)$ is equal to or less than $\$ 10.00$, each player will get the amount he or she claimed. If the total is more than $\$ 10.00$, neither student will receive any money.

Imagine that you are Player 2. Player 1 has claimed $\$ 8.00$ of the $\$ 10.00$. You can claim as much as you wish to claim, but if the addition of your claim (\$X) and Player 1's claim $(\$ 8.00)$ is more than $\$ 10.00$, then neither of you will receive money.

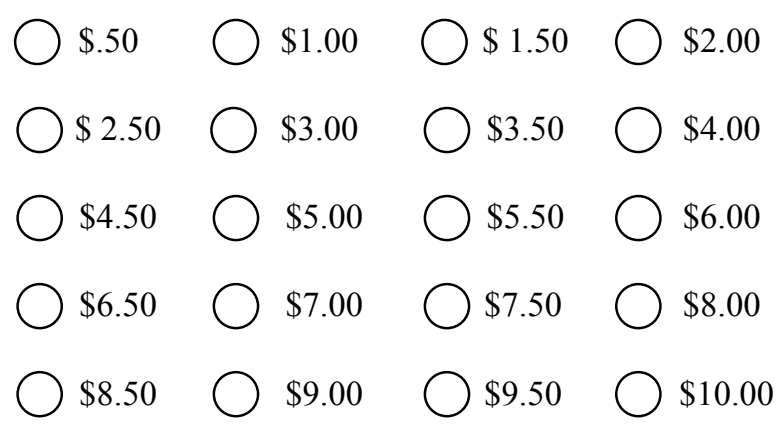

Reçu le 28 juillet 2009

Révision reçue le 4 janvier 2010 Accepté 10 février 2010 